Feature article

\title{
Role of oxygen on the phase stability and microstructure evolution of $\mathrm{CaCu}_{3} \mathrm{Ti}_{4} \mathrm{O}_{12}$ ceramics
}

\author{
Anderson A. Felix ${ }^{\mathrm{a}, *}$, Vinícius D.N. Bezzon ${ }^{\mathrm{a}}$, Marcelo O. Orlandi ${ }^{\mathrm{a}}$, Damjan Vengust ${ }^{\mathrm{b}}$, \\ Matjaž Spreitzer $^{\mathrm{b}}$, Elson Longo ${ }^{\mathrm{a}}$, Danilo Suvorov ${ }^{\mathrm{b}}$, José A. Varela ${ }^{\mathrm{a}}$ \\ a Physical Chemistry Department, Chemistry Institute, São Paulo State University (UNESP), Araraquara, São Paulo, Brazil \\ b Advanced Materials Department, Jožef Stefan Institute, Ljubljana, Slovenia
}

\section{A R T I C L E I N F O}

\section{Article history:}

Received 19 April 2016

Received in revised form 12 July 2016

Accepted 31 July 2016

Available online 9 August 2016

\section{Keywords:}

$\mathrm{CaCu}_{3} \mathrm{Ti}_{4} \mathrm{O}_{12}$

Oxygen partial pressure

Phase stability

Non-stoichiometry

Grain growth

\begin{abstract}
A B S T R A C T
Phase stability and microstructure evolution of polycrystalline $\mathrm{CaCu}_{3} \mathrm{Ti}_{4} \mathrm{O}_{12}$ (CCTO) ceramics were studied by controlling the partial pressure of oxygen (from a poor to an oxygen rich atmosphere) during the sintering process at high temperatures. The samples were analyzed by X-ray powder diffraction, scanning electron microscopy and X-ray energy dispersive spectroscopy. Our results show that the oxygen partial pressure during the sintering process is an important parameter that controls the phase stability, non-stoichiometry, and decomposition process of the CCTO phase as well as the densification and grain growth mechanisms on these polycrystalline ceramics. These results provided us further insight into the important role of copper reduction and copper/oxygen diffusion on the crystalline structure and morphological characteristics of polycrystalline CCTO ceramics.
\end{abstract}

(c) 2016 Elsevier Ltd. All rights reserved.

\section{Introduction}

In the last decades, high dielectric permittivity materials have been investigated extensively because of their potential for application in microelectronic devices [1]. Recently, $\mathrm{CaCu}_{3} \mathrm{Ti}_{4} \mathrm{O}_{12}$ (CCTO) has attracted scientific interest because of its large dielectric permittivity and non-linear current-voltage profile [2,3]. Several studies have shown that this perovskite can exhibit a dielectric permittivity of about $10^{4}-10^{5}$ for temperatures ranging from $100 \mathrm{~K}$ to $600 \mathrm{~K}$ without undergoing any phase transition $[2,4,5]$. On the other hand, non-linear current-voltage profiles have also been reported in ceramics [6], thin films [7,8] and recently in nanostructures [9] which are attributed to the conductivity on the film/metalelectrode interface and/or grain boundary mechanisms [10,11]. These properties make this material a promising candidate for applications in electronic devices such as capacitors, random access memories, microwave devices, and sensors [1-11].

However, the mechanisms responsible for these exceptional properties in CCTO ceramics are still not fully understood. Models based on oxygen loss or cation reduction have been related to the non-stoichiometry of the CCTO phase and have been used to explain the structural and electrical characteristics in this mate-

\footnotetext{
* Corresponding author.

E-mail address: aafelixy@yahoo.com.br (A.A. Felix).
}

rial [12]. The oxygen loss mechanism is commonly observed for many perovskite-based titanates when heated at high temperatures and/or treated in reducing atmospheres [13]. In this case, the hopping conductivity in CCTO has been related to the partial reduction of $\mathrm{Ti}^{4+}$ to $\mathrm{Ti}^{3+}$, which is compensated by the formation of oxygen vacancies because of oxygen loss from the lattice [14]. On the other hand, the copper reduction mechanism is based on the instability of $\mathrm{CuO}$ at high temperatures, leading to the formation of $\mathrm{Cu}_{2} \mathrm{O}$ at poor oxygen concentrations, and it is also associated with the instability of the CCTO phase $[15,16]$. Furthermore, the n-type conductivity in this material is attributed to the reduction of $\mathrm{Cu}^{2+}$ to $\mathrm{Cu}^{1+}$ during sintering between 950 and $1100^{\circ} \mathrm{C}$ in air [17], whereas at similar sintering conditions, oxidation of $\mathrm{Cu}^{2+}$ to $\mathrm{Cu}^{3+}$ is proposed to explain the p-type conductivity in CCTO $[12,18]$. Both models have been proposed based mainly on the electrical measurements of the post-annealing samples because of the difficulty in distinguishing the contribution of each model by direct chemical analysis of the CCTO samples. Moreover, to the best of our knowledge, the influence of both mechanisms as a function of a broad range of oxygen partial pressures during the sintering process as well as its effects on the structural and morphological characteristics of CCTO ceramics has not been systematically investigated.

In the light of these shortcomings, the main goal of this study was to investigate how controlled variations of the oxygen content in the $\mathrm{CaCu}_{3} \mathrm{Ti}_{4} \mathrm{O}_{12}$ phase may influence the phase stability, crystalline structure, and the microstructure of polycrystalline ceramics 
prepared by the solid-state reaction method. The samples were sintered at different oxygen partial pressures and analyzed by X-ray powder diffraction (XRPD), scanning electron microscopy (SEM), and X-ray energy dispersive spectroscopy (EDS). This study provides a deeper understanding of the important role of copper reduction and copper/oxygen diffusion on the phase stability, structural, and morphological characteristics of polycrystalline CCTO ceramics.

\section{Experimental procedure}

\subsection{Synthesis procedure}

Polycrystalline CCTO bulk samples were prepared by a solidstate reaction method [19]. Analytical grade $\mathrm{CaCO}_{3}$ (Aldrich, 99.99\%), $\mathrm{TiO}_{2}$ (Aldrich, 99.99\%), and $\mathrm{CuO}$ (Aldrich, 99.99\%) powders were used to prepare the CCTO powders. The raw materials were milled in an isopropanol suspension for $24 \mathrm{~h}$ with yttriumstabilized zirconia balls inside a polyethylene bottle. The resulting product was dried at $50{ }^{\circ} \mathrm{C}$ and annealed at $900^{\circ} \mathrm{C}$ for $12 \mathrm{~h}$ in air. This calcination temperature was determined by thermo gravimetric analysis (TG) and differential thermal analysis (DTA) (Netzsch, Model STA 409), as shown in Fig. S1 in Supplementary material. After the calcination, ССТО powders were ground to obtain an average particle size of about $1 \mu \mathrm{m}$, determined by laser scattering particle size distribution analyzer (Horiba, Model LA-920) (see Fig. S2). Then, the powders were uniaxially pressed at $1 \mathrm{MPa}$ into disks, $8 \mathrm{~mm}$ in diameter and $1 \mathrm{~mm}$ thick, and further isostatically pressed to $200 \mathrm{MPa}$. The pellets were sintered at $1100^{\circ} \mathrm{C}$ for $3 \mathrm{~h}$ at heating and cooling rates of $10^{\circ} \mathrm{C} / \mathrm{min}$ using a controlled dynamical atmosphere in a tube furnace. The oxygen partial pressure in the sintering atmosphere was controlled by the injection of mixed $\mathrm{N}_{2}$ and $\mathrm{O}_{2}$ gases, measured by mass flow controllers (MKS), with a constant flux of $100 \mathrm{sccm}$. The following oxygen partial pressures, with the respective sample's acronyms in parentheses, were used during the sintering process: $0.001 \% \mathrm{pO}_{2}$ (CCTON2), $1.0 \% \mathrm{pO}_{2}$ (CCTO1), $5.0 \%$ $\mathrm{pO}_{2}$ (CCTO5), 7.5\% $\mathrm{pO}_{2}$ (CCTO8), $10.0 \% \mathrm{pO}_{2}$ (CCTO10); $21.0 \% \mathrm{pO}_{2}$ (CCTO21), 50.0\% $\mathrm{pO}_{2}$ (CCTO50), 75.0\% $\mathrm{pO}_{2}$ (CCTO75), and $100.0 \%$ $\mathrm{pO}_{2}$ (CCTO100).

\subsection{Characterizations}

Phase analysis of the CCTO powders and pellets was performed by X-ray powder diffraction (XRPD) using a RINT2000 diffractometer from Rigaku (Tokyo, Japan) operating in the reflection mode with a $\mathrm{CuK \alpha}$ source and over the $2 \theta$ range of $15^{\circ}$ to $115^{\circ}$ with a step size of $0.02^{\circ}$. A divergence slit of $0.5^{\circ}$ was used, and the sample was placed in a rotation sample holder with a constant rotation of $20 \mathrm{rpm}$. The XRPD detection limit for the equipment used in this work was estimated to be $1 \mathrm{wt} \%$ [20].

Structure refinements were performed by the Rietveld method (RM) using the XRPD data [21-24]. The refinements were performed using the fundamental parameters approach implemented in the Topas Academic V.5 software [25,26], in which the structure parameters of $\mathrm{CaCu}_{3} \mathrm{Ti}_{4} \mathrm{O}_{12}$ [2], $\mathrm{CaTiO}_{3}$ [27], $\mathrm{TiO}_{2}$ [28], $\mathrm{CuO}$ [29] and $\mathrm{Cu}_{2} \mathrm{O}[30]$ used in the refinements were obtained from the Inorganic Crystal Structure Database (ICSD). In all the refinements, the background was fitted using a Chebyshev polynomial function with six terms. The refinements in this work were focused on obtaining the lattice parameters and the relative quantity phases.

The microstructure of the CCTO pellets was analyzed using an field emission scanning electron microscope (FESEM) (JEOL, Model $7500 \mathrm{~F}$ ) equipped with an X-ray energy dispersive spectrometer (EDS) (Thermo Scientific, Model Ultra Dry). For SEM analysis, the surface of the ceramics was polished using diamond paste. Based on

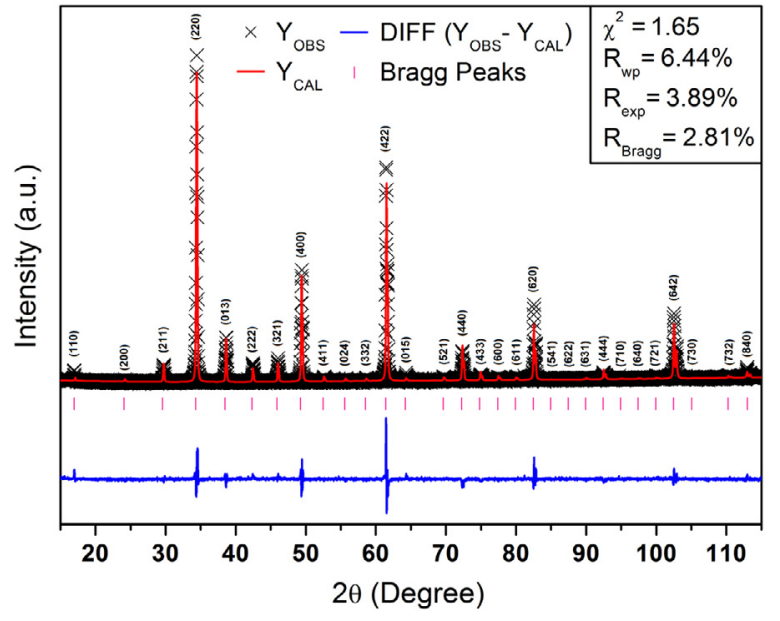

Fig. 1. XRPD pattern for CCTO powders after calcination performed at $900{ }^{\circ} \mathrm{C}$ for $12 \mathrm{~h}$ in air. Right inset: Agreement factors of the Rietveld refinement.

our results (discussed below), we determined that thermal etching at $975^{\circ} \mathrm{C}$ for $20 \mathrm{~min}$ in air atmosphere was the best etching condition for all the samples analyzed here. The relative density of the samples was estimated using the Archimedes method.

\section{Results and discussion}

\subsection{Influence of oxygen on the stability of the CCTO phase}

Fig. 1 shows a typical XRPD pattern of the CCTO powders annealed at $900{ }^{\circ} \mathrm{C}$ for $12 \mathrm{~h}$. The diffraction peaks can be indexed by the cubic body-centered perovskite-related structure, $\mathrm{CaCu}_{3} \mathrm{Ti}_{4} \mathrm{O}_{12}$, in accordance with the Joint Committee on Powder Diffraction Standards (JCPDS) card \#75-2188 in which all planes are indexed. The obtained CCTO powders are free of secondary phases, according to the XRPD detection limit, and the relative peak intensities indicate a polycrystalline sample without any preferential orientation. Rietveld refinements were performed by the cubic structure of space group Im-3 with a lattice parameter of 7.39347(3) $\AA$ [2], and the calculated pattern is shown in Fig. 1. The agreement factors (see right inset in Fig. 1) show an excellent agreement between the experimental and calculated patterns in which the calculated lattice parameter was 7.3956(8) $\AA$, which is larger than the initial structure, and is expected for a powder material when compared to dense pellets sintered at high temperatures [2].

XRPD patterns of the sintered CCTO pellets at different oxygen partial pressures are shown in Figs. 2 and S3. XRPD patterns for the samples sintered from 10 to $100 \% \mathrm{pO}_{2}$ exhibited only the $\mathrm{CaCu}_{3} \mathrm{Ti}_{4} \mathrm{O}_{12}$ perovskite phase (based on the XRPD detection limit), the same phase observed in the starting CCTO powder, without any preferential orientation. However, the formation of $\mathrm{CaCu}_{3} \mathrm{Ti}_{4} \mathrm{O}_{12}$ coexisting with the phases $\mathrm{CaTiO}_{3}$ (JCPDS card \#89-6949), $\mathrm{TiO}_{2}$ (JCPDS card \#21-1276), $\mathrm{CuO}$ (JCPDS card \#89-5895), and $\mathrm{Cu}_{2} \mathrm{O}$ (JCPDS card \#78-2076) were noted on the samples sintered from 1 to $7.5 \% \mathrm{pO}_{2}$. Finally, the sample sintered at $0.001 \% \mathrm{pO}_{2}$ does not exhibit any peak related to the CCTO phase.

Rietveld refinement was performed for all the samples to obtain the structure parameters and quantitative phase analysis as a function of the oxygen partial pressure. The agreement factor values $\left(R_{w p}, R_{\text {exp }}, R_{B r a g g}\right.$, and $\left.\chi^{2}\right)$ of the refinements confirmed a very good agreement between the experimental and calculated patterns, as shown in Table 1. Structure refinement data showed that the samples sintered under $10-100 \% \mathrm{pO}_{2}$ were crystallized in the CCTO cubic phase without any secondary phase. The relative quantity of the phases at $7.5 \% \mathrm{pO}_{2}$ indicates the predominant formation of 

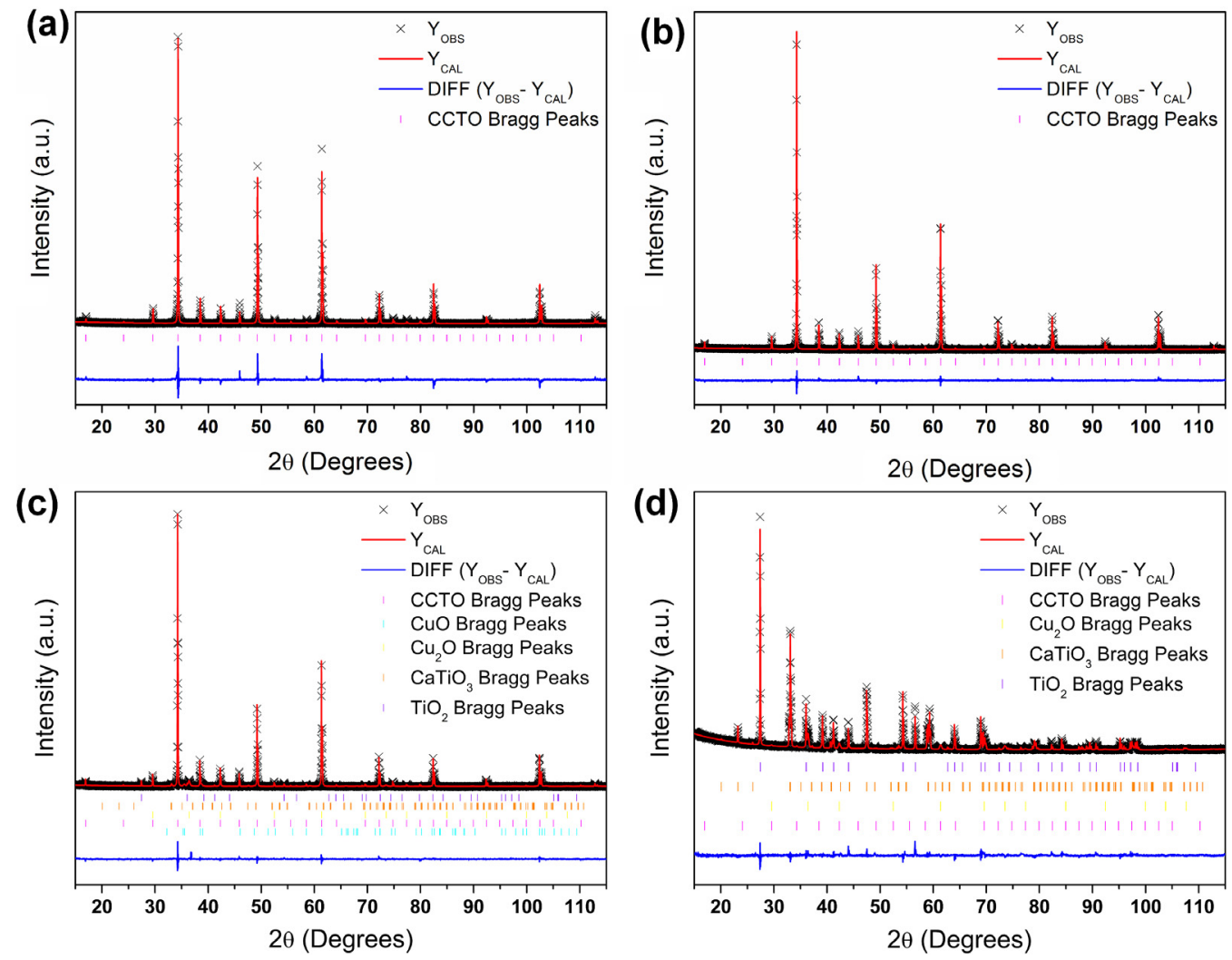

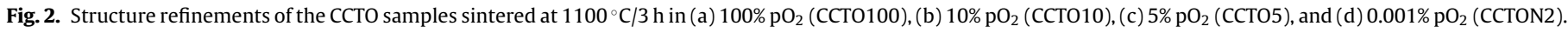

Table 1

Relative quantity of the phases and quality parameters of the structural refinements for the CCTO samples sintered at different oxygen partial pressures.

\begin{tabular}{|c|c|c|c|c|c|c|}
\hline Samples & Phases & wt (\%) & $\mathrm{R}_{\text {Bragg }}(\%)$ & $\mathrm{X}^{2}$ & $\mathrm{R}_{\mathrm{wp}}(\%)$ & $\mathrm{R}_{\exp }(\%)$ \\
\hline ССТ0100 & ССТО & 100 & 4.82 & 1.46 & 7.29 & 4.98 \\
\hline ССТ075 & ССТО & 100 & 3.43 & 1.27 & 6.02 & 4.75 \\
\hline ССТО50 & ССТО & 100 & 4.07 & 1.34 & 7.11 & 5.29 \\
\hline ССТО21 & ССТО & 100 & 1.90 & 1.12 & 5.45 & 4.85 \\
\hline ССТО10 & ССТО & 100 & 7.43 & 1.51 & 7.33 & 4.85 \\
\hline \multirow[t]{2}{*}{ ССТО 8} & ССТО & $94.1(3)$ & 4.60 & 1.23 & 5.70 & 4.64 \\
\hline & $\mathrm{CuO}$ & $5.9(3)$ & 1.41 & & & \\
\hline \multirow[t]{5}{*}{ СCTO5 } & ССТО & $87.7(2)$ & 1.66 & 1.15 & 5.26 & 4.59 \\
\hline & $\mathrm{CuO}$ & $3.5(2)$ & 0.64 & & & \\
\hline & $\mathrm{Cu}_{2} \mathrm{O}$ & $4.3(8)$ & 1.54 & & & \\
\hline & $\mathrm{CaTiO}_{3}$ & $2.1(11)$ & 2.15 & & & \\
\hline & $\mathrm{TiO}_{2}$ & $2.4(8)$ & 3.58 & & & \\
\hline \multirow[t]{4}{*}{ ССТ01 } & ССТО & $8.2(2)$ & 7.62 & 1.67 & 8.38 & 5.01 \\
\hline & $\mathrm{Cu}_{2} \mathrm{O}$ & $14.4(2)$ & 5.48 & & & \\
\hline & $\mathrm{CaTiO}_{3}$ & $48.4(3)$ & 3.01 & & & \\
\hline & $\mathrm{TiO}_{2}$ & $28.9(4)$ & 5.21 & & & \\
\hline \multirow[t]{3}{*}{$\mathrm{CCTON}_{2}$} & $\mathrm{Cu}_{2} \mathrm{O}$ & $4.2(7)$ & 5.42 & 1.44 & 9.33 & 6.46 \\
\hline & $\mathrm{CaTiO}_{3}$ & $52.1(3)$ & 4.17 & & & \\
\hline & $\mathrm{TiO}_{2}$ & 43.7 (3) & 5.74 & & & \\
\hline
\end{tabular}

CCTO, which coexists only with the $\mathrm{CuO}$ phase. Then, from 1 to $5 \% \mathrm{pO}_{2}$, there is an increased formation of the $\mathrm{CaTiO}_{3}, \mathrm{TiO}_{2}$, and $\mathrm{Cu}_{2} \mathrm{O}$ phases with a decreasing amount of the CCTO phase, which is completely decomposed at $0.001 \% \mathrm{pO}_{2}$. In addition, as observed in Fig. 3, the CСTO lattice parameter increased and the phase density decreased with decreasing oxygen partial pressure, indicating that the unit cell expands when the oxygen partial pressure decreases.

Before we conclude that our samples are single-phase above $10 \% \mathrm{pO}_{2}, \mathrm{SEM}$ analysis was used to confirm the XRPD results and to study the microstructure of the pellets. It is well known that by using a backscattered electrons (BSE) detector in the SEM it is pos- sible to detect small amounts of secondary phases, if the average atomic number of each phase is different [31]. As-polished surface BSE-SEM images of the CCTO samples sintered at different oxygen partial pressures are shown in Fig. S4. The samples sintered at high oxygen partial pressure consist of single-phase materials, while traces of inhomogeneity are observed in samples sintered at 21 and $10 \% \mathrm{pO}_{2}$. Although XRPD analysis did not reveal any secondary phases for these samples, EDS performed on the small brighter grains indicated a copper-rich phase, as shown in Fig. S5. Most probably, these grains consist of $\mathrm{CuO}$, since this phase was 


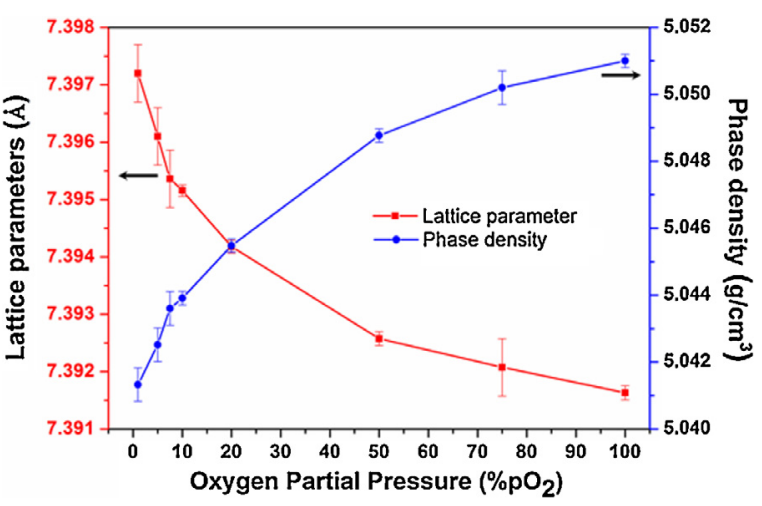

Fig. 3. Lattice parameter and phase density as a function of the oxygen partial pressure.

observed down to $7.5 \% \mathrm{pO}_{2}$, and further reduction to $\mathrm{Cu}_{2} \mathrm{O}$ should only be observed at oxygen partial pressures lower than $5 \% \mathrm{pO}_{2}$.

Keeping in mind that the starting powder is composed of a CCTO single-phase, XRPD results indicate that the CCTO phase has decomposed gradually into the secondary phases at oxygen concentrations lower than $7.5 \% \mathrm{pO}_{2}$. Moreover, the lattice parameter, and, consequently, the unit cell volume increased with decreasing oxygen partial pressure until the complete decomposition of the remaining CCTO phase (see Fig. 3). This may point to a threshold concentration of ions and defects, which makes the crystalline structure of CCTO stable, with the stoichiometry of the phase depending on the oxygen content.

Non-stoichiometry of the CСТO phase has been reported to be related to the chemical inhomogeneity on the crystalline lattice due to copper and titanium reduction and/or oxygen loss [12]. In our study, the presence of the $\mathrm{CuO}$ phase after sintering below $21 \%$ $\mathrm{pO}_{2}$ and the further reduction to $\mathrm{Cu}_{2} \mathrm{O}$ in the oxygen-poor concentrations implies that the oxygen loss from the crystalline lattice is the main mechanism controlling the non-stoichiometry and the decomposition process observed in CCTO ceramics. In intermediate oxygen concentrations, the CCTO is stable but non-stoichiometric because of the oxygen loss from the lattice, which induces segregation of the $\mathrm{CuO}$-rich phase at the grain boundary regions leading to a copper deficiency on the crystalline lattice [12]. In the oxygen-poor concentrations, the oxygen loss from the lattice increases significantly, inducing copper reduction and leading to a defect-induced decomposition process of the CCTO phase [16]. Moreover, the formation of $\mathrm{CaTiO}_{3}$ and $\mathrm{TiO}_{2}$ instead of any other reduced titanium phase during decomposition may indicate a minor contribution of titanium to the decomposition process of the CCTO phase. On the other hand, the absence of the CuO-rich phase at the oxygenrich concentrations indicates that the chemical homogeneity of the CCTO phase may be maximized during the sintering process at these conditions, thus, avoiding the cation deficiency on the CСTO lattice. However, the presence of reduced titanium and copper cations as well as oxygen-related defects on the CCTO lattice cannot be ruled out, and it will be investigated further systematically as a function of the oxygen partial pressure using spectroscopic techniques.

In summary, our detailed study indicates that $\mathrm{CaCu}_{3} \mathrm{Ti}_{4} \mathrm{O}_{12}$ is stable above $7.5 \% \mathrm{pO}_{2}$ with the stoichiometry of the phase being oxygen-dependent. The CCTO structure starts to decompose gradually with lowering of the oxygen partial pressure below $7.5 \% \mathrm{pO}_{2}$, and at pressures lower than $1.0 \% \mathrm{pO}_{2}$, defect-induced degradation completely decomposes the CCTO phase, which is directly related to the oxygen loss from the CCTO crystalline lattice and copper reduction. These results are in agreement with the phase stability model proposed by Jacob et al. based on the ternary phase diagram of $\mathrm{CaO}-\mathrm{CuO}-\mathrm{TiO}_{2}$ suggesting that $\mathrm{CaCu}_{3} \mathrm{Ti}_{4} \mathrm{O}_{12}$ is not stable at oxygen concentrations lower than $0.3 \% \mathrm{pO}_{2}$, whereas it can coexist with other intermediate phases above this concentration [16,32]. Our findings suggest that the copper deficiency/reduction is intimately linked with the oxygen loss; this being one of the main mechanisms controlling the stability and non-stoichiometry of the CCTO phase.

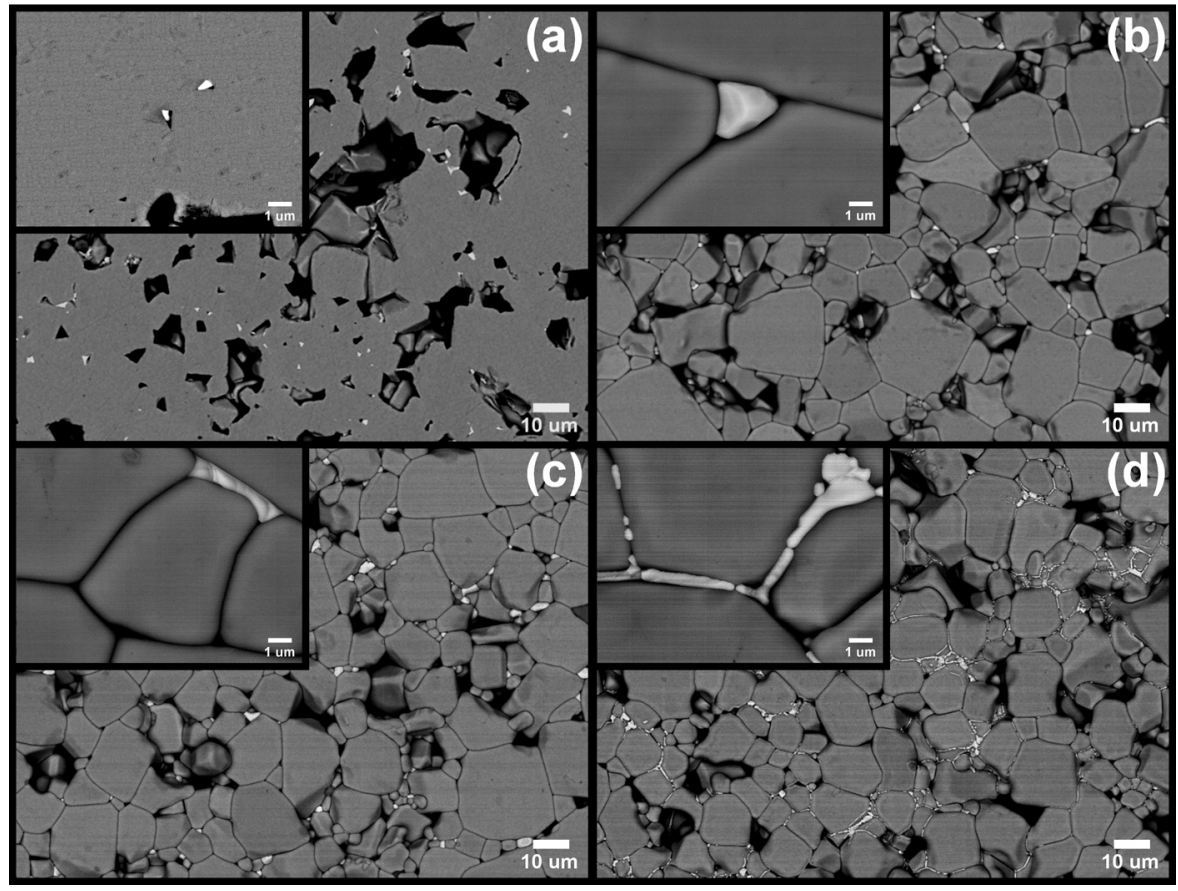

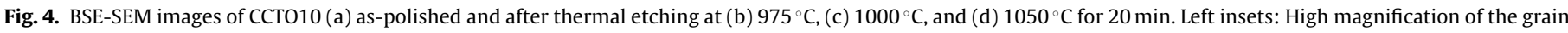
boundary regions. 


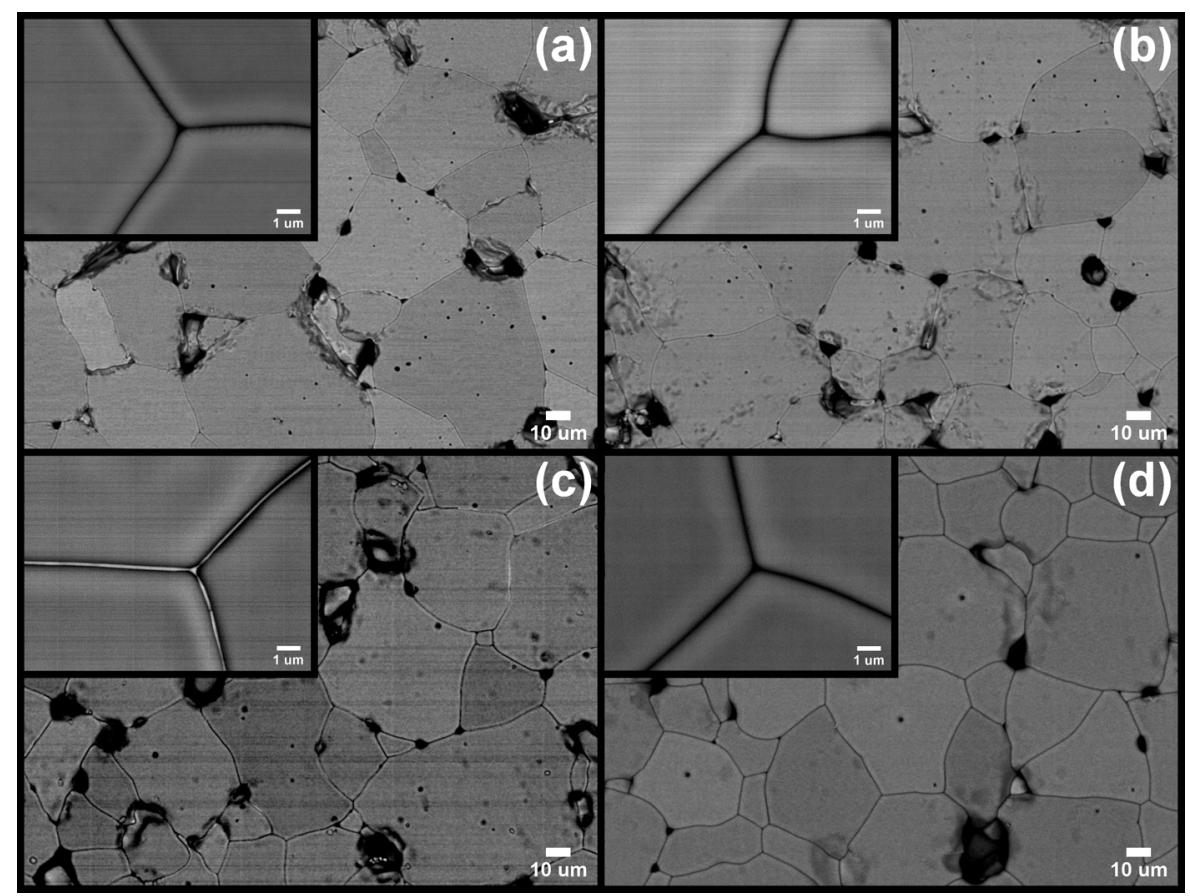

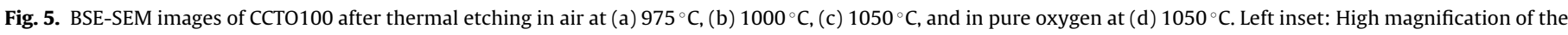
grain boundary regions.

\subsection{Influence of oxygen on the microstructure evolution of the CCTO phase}

\subsubsection{Effect of thermal etching on microstructure}

It is well known that SEM sample preparation can induce the formation of secondary phases at the grain boundary regions depending on the time and temperature of the thermal etching process [33]. Once we ruled out chemical etching, after trying different types of acid and basic solutions, we performed a case study to find the conditions where grain boundaries in CCTO ceramics can be observed without significant changes in the microstructure and composition.

Fig. 4 shows the SEM images of the CCTO10 sample sintered at $1100^{\circ} \mathrm{C}$ after thermal etching at different temperatures for $20 \mathrm{~min}$ in air. Our study showed that grain boundaries were observed at temperatures above $975^{\circ} \mathrm{C}$ (Fig. $4 \mathrm{~b}$ ), in which small copper grains similar to those seen in the unetched samples (see Figs. S4 and 4 a) can be observed, located mainly at the triple points of the grain boundary region. However, at temperatures above $1000^{\circ} \mathrm{C}$ (Fig. 4c), some copper grains became elongated, indicating that $\mathrm{CuO}$ liquefies over the entire grain boundary region, as confirmed by the line scan EDS analysis shown in Fig. S5. This effect is more pronounced at $1050^{\circ} \mathrm{C}$, where most of the $\mathrm{CuO}$ grains become elongated (Fig. $4 \mathrm{~d}$ ). In addition, as shown in Fig. 5, a thin CuO layer at the grain boundaries is only present on the CCTO100 sample when thermal etching is performed at $1050^{\circ} \mathrm{C}$ in air (Fig. 5c). For etching at temperatures below $1050^{\circ} \mathrm{C}$ in air (Fig. $5 \mathrm{a}$ and b) or at $1050^{\circ} \mathrm{C}$ in pure oxygen (Fig. 5d), the copper-rich phase is absent.

These results indicate that the use of lower oxygen concentrations during thermal etching allows copper diffusion from the grain bulk outward to the grain boundary region at high temperatures, even if the sample has been sintered at oxygen-rich concentrations. Additionally, the etching at the oxygen-rich concentrations can prevent copper diffusion and secondary phase formation. These results corroborate the work reported by Kim et al., in which, the formation of a thin copper-rich layer at the grain boundary regions during thermal etching in air at $1020^{\circ} \mathrm{C}$ was observed in CCTO ceramics that were also sintered in air [34]. Thus, we believe that the formation of a $\mathrm{CuO}$ liquid phase over the entire grain boundary region during thermal etching can occur in CCTO samples because of the melting of a pre-existing $\mathrm{CuO}$ phase from the sintering process and/or by copper diffusion during thermal etching, in which, the relationship between the oxygen concentration during the sintering process and thermal etching at high temperatures has a direct influence on the gradient of the copper diffusion in CCTO ceramics.

In summary, our results indicate that thermal etching (and probably post-annealing treatments) is time-, temperature-, and oxygen concentration-dependent, and thus, must be performed at as low a temperature, for shorter time, and at controlled oxygen atmosphere in order to avoid significant changes on the ceramic microstructure that could lead to questionable interpretations.

\subsubsection{Study of densification and grain growth mechanisms}

It is well established in the ceramics processing that the densification and grain growth mechanisms are time- and temperature-dependent [35,36]. Thus, our samples were prepared keeping the time $(3 \mathrm{~h})$ and temperature $\left(1100^{\circ} \mathrm{C}\right)$ constant and by changing the oxygen partial pressure during the sintering process, aiming for a deeper understanding of the role of oxygen on the densification and grain growth mechanisms in CCTO ceramics.

In the sample sintered at $0.001 \% \mathrm{pO}_{2}$ (CCTON2), mapped X-ray line intensities (see Fig. S6), which correspond to the amount of the three different elements, suggest that only three different phases are present. Based on both the EDS analysis and the BSE image (Fig. 6a), we can conclude that: i) The bigger dark-gray grains are composed mainly of Ti atoms; ii) the smaller white grains are composed of a Cu-rich phase, and are distributed around the dark-gray grains; iii) the smaller light-gray grains are composed of $\mathrm{Ca}$ and $\mathrm{Ti}$ atoms, and are distributed around the white and dark-gray grains. These data corroborate with the XRPD data indicating that this sample was crystallized in the $\mathrm{CaTiO}_{3}, \mathrm{TiO}_{2}$ and $\mathrm{Cu}_{2} \mathrm{O}$ phases and no CCTO phase was present, confirming the complete decomposition of the initial CCTO phase during the sintering process [16]. In addi- 


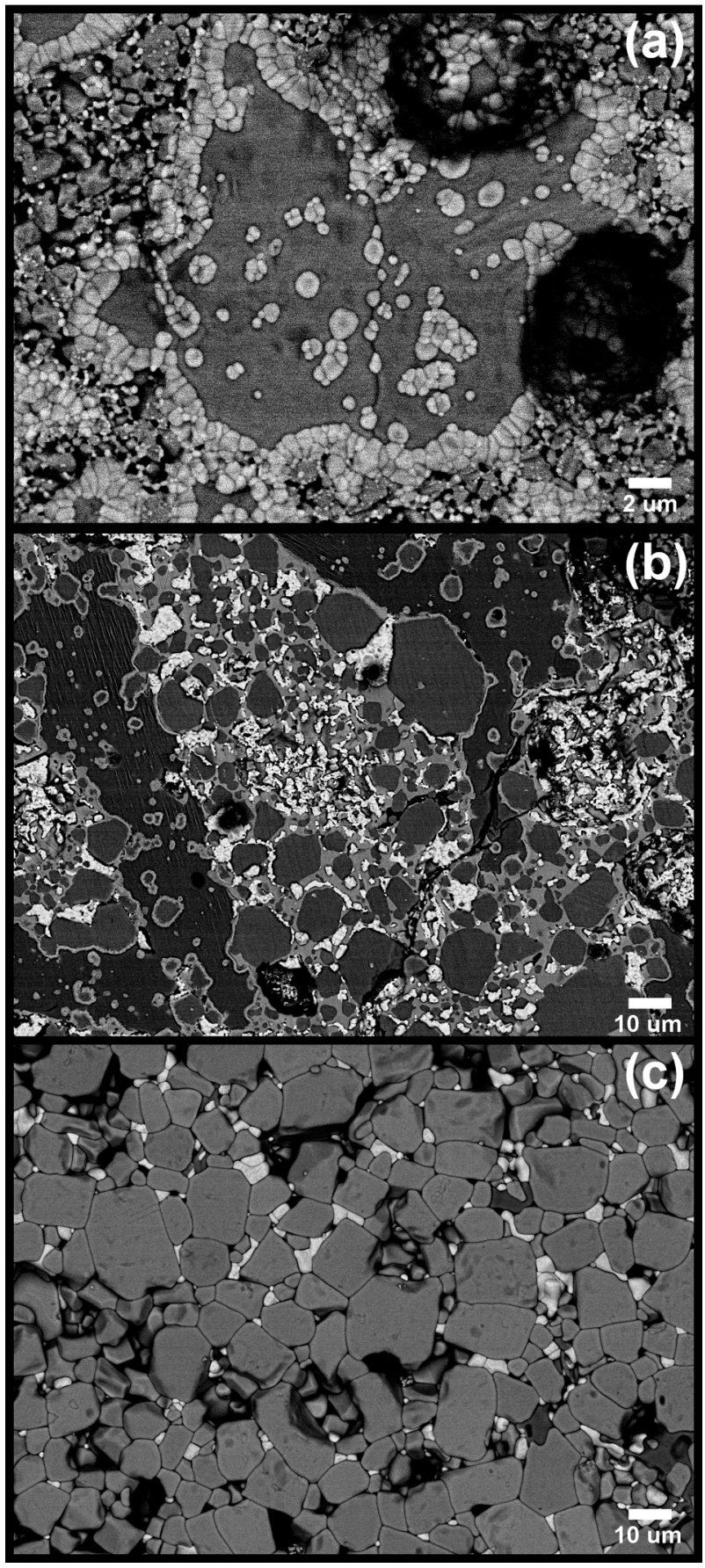

Fig. 6. BSE-SEM images of the CCTO samples sintered at $1100{ }^{\circ} \mathrm{C} / 3 \mathrm{~h}$ in (a) $0.001 \%$ $\mathrm{pO}_{2}$, (b) $1.0 \% \mathrm{pO}_{2}$, and (c) $5 \% \mathrm{pO}_{2}$.

tion, as shown in Figs. 6 b,c and S7, the coexistence of the $\mathrm{CaTiO}_{3}$, $\mathrm{TiO}_{2}, \mathrm{Cu}_{2} \mathrm{O}$, and CCTO phases is also evidenced on samples CCTO 1 and CCTO5. The high porosity and low relative density (see Table 2) of these samples may indicate that the grain growth of the CCTO phase occurs by a non-densification mechanism at oxygen-poor concentrations.

Figs. 7 and S8 show the SEM images of the CCTO samples sintered at intermediate and oxygen-rich concentrations and their respective grain size distribution. The increasing of oxygen content up to $21 \% \mathrm{pO}_{2}$ reduced the amount of $\mathrm{CuO}$ secondary phase, and the average CCTO grain size increased (see Table 2), exhibiting a monomodal distribution. This grain growth process is related to a densification mechanism leading to a decrease in the sample
Table 2

Morphological parameters of the CCTO samples prepared at different oxygen partial pressures.

\begin{tabular}{lll}
\hline Samples & Average CCTO grain size $(\mu \mathrm{m})^{\mathrm{a}}$ & Relative density $(\%)$ \\
\hline CCTON2 & - & 61 \\
CСTO1 & - & 73 \\
CCTO5 & - & 79 \\
CСTO8 & 9 & 87 \\
CCTO10 & 10 & 88 \\
CСTO21 & 12 & 89 \\
CСTO50 & 15 & 91 \\
CСTO75 & 23 & 93 \\
CСT0100 & 41 & 95 \\
\hline
\end{tabular}

a Extracted from the statistical distribution shown in Fig. 7.

porosity. Additional increase in the oxygen content above $50 \% \mathrm{pO}_{2}$ induced an exaggerated increase in grain size, generating a bimodal distribution and a high decrease in the sample porosity (Fig. S4), which indicates a different coarsening process of the grains at the oxygen-rich concentrations. Besides, these results are in agreement with the relative density data, shown in Table 2, which indicates that the samples become denser with an increase in the oxygen partial pressure during the sintering process.

Modeling of the densification and grain growth is not easy when more than one mass transport mechanism contributes to the changes in the ceramic microstructure [35,37]. In our samples, the time and temperature of sintering were kept constant for all samples, so it was clearly observed that the oxygen partial pressure during the sintering process is directly related not only to the CCTO phase stability but also to the main mechanism of densification and grain growth. Based on the thermal etching results, we hypothesize that the oxygen concentration during the sintering process plays an important role on the gradient diffusion of oxygen and copper in the CCTO lattice, which leads to a different mass transport mechanism on the lattice, and consequently, to different densification and grain growth processes during sintering.

At oxygen-poor concentrations (up to $5 \% \mathrm{pO}_{2}$ ), we suppose that the mass transport may be controlled by the evaporation and condensation mechanism, which is a non-densification mechanism, leading to the formation of samples with a lower relative density $[38,39]$. At high temperature and lower oxygen partial pressure, the high vapor transport of, most probably copper, across the surface can contribute significantly to the sublimation of the material inducing CCTO phase decomposition and leading to samples with high porosity and low volume shrinkage.

On the other hand, for intermediate and oxygen-rich concentrations, CCTO is a stable phase, enabling a better understanding of the mechanisms of densification and grain growth. The growth of $\mathrm{CuO}$ phase inclusions at the triple point of the grain boundary regions indicates a diffusion of copper ions from the CCTO bulk outward to the grain boundary regions, in accordance with our etching study, generating a non-stoichiometric CCTO phase, as discussed above [12]. The $\mathrm{CuO}$ inclusions, which have a smaller grain size than the CCTO grains, combined with the high density of pores may retard the grain boundary movement, i.e., the pores and inclusions intersecting the grain boundaries exert a drag force on the boundary and reduce its effective mobility, which delays the normal grain growth of the main CCTO phase [40,41]. This suggests that the grain growth is pinned by the inclusions because it is less pronounced with the increasing in the oxygen concentration, where the amount of the $\mathrm{CuO}$ secondary phase is smaller. Hence, we believe that the dominant mass transport mechanism at intermediate oxygen concentrations may be related to the lattice diffusion process [42], which is a densification mechanism of sintering but leads to less pronounced densification processes than the grain boundary diffusion process [35]. 


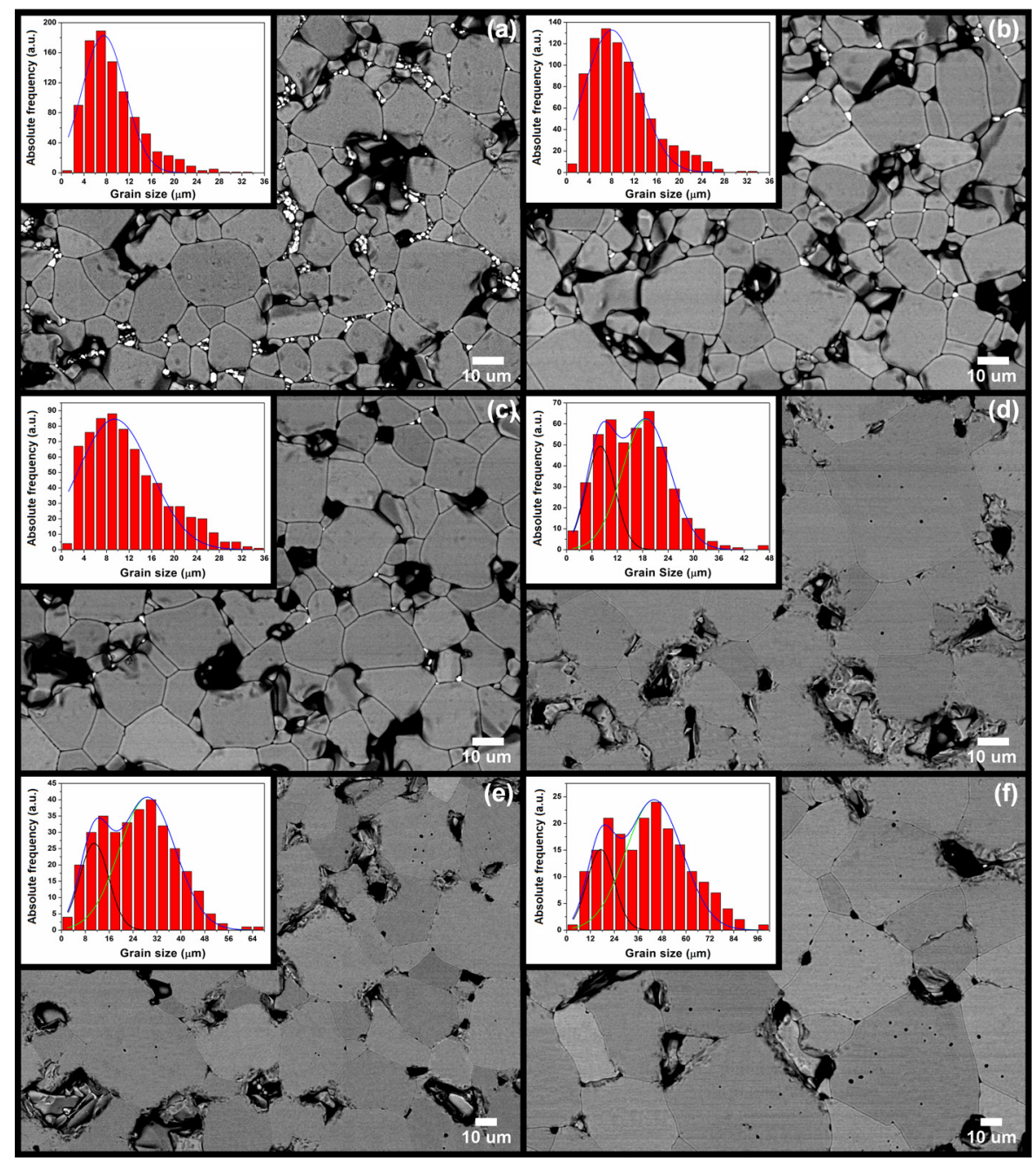

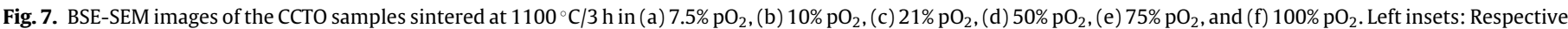
grain size distribution of each sample.

For oxygen-rich concentrations, the $\mathrm{CuO}$ inclusions disappeared in all the samples indicating that copper diffusion from the CCTO bulk outward to the grain boundary regions was controlled by the oxygen diffusion into the CCTO bulk, in accordance with the etching results. Moreover, the presence of intragranular pores suggests a faster grain growth and slower pore diffusion [42]. These results show that the densification process at the oxygen-rich concentrations may be dominated by the grain boundary diffusion mechanism, which allows faster grain growth and higher volume shrinkage than the lattice diffusion process [35,36].

In addition, a bimodal grain size distribution indicates an abnormal grain growth (AGG) at the oxygen-rich concentrations [37,43]. This type of grain growth has been observed by other authors at different times and temperatures of sintering in the CCTO samples $[34,44]$. AGG is reported to occur in polycrystalline ceramics because of different parameters such as critical mean grain radius, distribution grain width, and pinning effect [45-47]. Moreover, Kim et al. have reported that AGG can be controlled by the addition of $\mathrm{SiO}_{2}$ into a CCTO matrix because of the formation of a copper/silicon-based phase at the grain boundary region [48]. Thus, we believe that the AGG in CCTO ceramics can be controlled by the oxygen content during the sintering process because of the ability to control the copper/oxygen diffusivity at high temperatures, and consequently, the pinning effect originating from the segregation of the copper-rich phases at intermediate oxygen concentrations.
To summarize, our results indicate that oxygen partial pressure during the sintering process of CCTO pellets has a large influence on the densification, and consequently, on the grain growth mechanisms, by controlling the diffusion gradient of oxygen and copper in polycrystalline CCTO ceramics prepared at high temperatures by the solid-state reaction.

\section{Conclusion}

Polycrystalline CCTO ceramics were prepared by a solid-state reaction at different oxygen partial pressures. XRPD and SEM results indicate that the CCTO phase is stable at oxygen concentrations ranging from $7.5 \%$ to $100 \% \mathrm{pO}_{2}$, and becomes highly unstable when sintered at oxygen partial pressures below 5\%, decomposing completely at a concentration of about $0.001 \% \mathrm{pO}_{2}$. The oxygen partial pressure also influences the microstructure evolution of the CCTO phase during the sintering process, by controlling the densification and grain growth mechanisms. The copper diffusivity on the CCTO lattice is controlled by the oxygen diffusivity during the sintering process, which controls the mass transport on the grain boundary regions, and consequently, the grain growth mechanism, leading to a normal grain growth, influenced by a pinning effect of the copper-rich secondary phase, or an abnormal grain growth. However, before one can determine whether this oxygen/copper relationship has any influence on the dielectric and electrical prop- 
erties of CCTO ceramics, additional studies, which are already in progress, must be performed in order to deconvolute the formation of chemical and electronic defects on the CCTO phase as a function of the oxygen partial pressure during the sintering process.

\section{Acknowledgements}

The authors gratefully acknowledge the financial support of the São Paulo Research Foundation (FAPESP) (Grant numbers: 09/00367-6, 13/14647-6 and 13/07296-2) and The National Council for Scientific and Technological Development (CNPq) (Grant numbers: $165902 / 2015-9$ and 2012/51195-3) in the development of this work.

\section{Appendix A. Supplementary data}

Supplementary data associated with this article can be found, in the online version, at http://dx.doi.org/10.1016/j.jeurceramsoc. 2016.07.039.

\section{References}

[1] D.E. Kotecki, A review of high dielectric materials for DRAM capacitors, Integr. Ferroelectr. 16 (1-4) (1997) 1-19.

[2] M.A. Subramanian, D. Li, N. Duan, B.A. Reisner, A.W. Sleight, High dielectric constant in $\mathrm{ACu}_{3} \mathrm{Ti}_{4} \mathrm{O}_{12}$ and $\mathrm{ACu}_{3} \mathrm{Ti}_{3} \mathrm{FeO}_{12}$ phases, J. Solid State Chem. 151 (2) (2000) 323-325.

[3] M.A.L. Cordeiro, F.L. Souza, E.R. Leite, A.J.C. Lanfredi, Anomalous current-voltage behavior of $\mathrm{CaCu}_{3} \mathrm{Ti}_{4} \mathrm{O}_{12}$ ceramics, Appl. Phys. Lett. 93 (18) (2008) 182912,3pp.

[4] C.C. Homes, T. Vogt, S.M. Shapiro, S. Wakimoto, A.P. Ramirez, Optical response of high-dielectric-constant perovskite-related oxide, Science 293 (5530) (2001) 673-676.

[5] A.P. Ramirez, M.A. Subramanian, M. Gardel, G. Blumberg, D. Li, T. Vogt, S.M. Shapiro, Giant dielectric constant response in a copper-titanate, Solid State Commun. 115 (5) (2000) 217-220.

[6] X.J. Luo, C.P. Yang, S.S. Chen, X.P. Song, H. Wang, K. Baerner, The trap state relaxation related polarization in $\mathrm{CaCu}_{3} \mathrm{Ti}_{4} \mathrm{O}_{12}$, J. Appl. Phys. 108 (1) (2010) 014107.

[7] Y.S. Shen, B.S. Chiou, C.C. Ho, Effects of annealing temperature on the resistance switching behavior of $\mathrm{CaCu}_{3} \mathrm{Ti}_{4} \mathrm{O}_{12}$ films, Thin Solid Films 517 (3) (2008) 1209-1213.

[8] A.A. Felix, J.L.M. Rupp, J.A. Varela, M.O. Orlandi, Multi-functional properties of $\mathrm{CaCu}_{3} \mathrm{Ti}_{4} \mathrm{O}_{12}$ J. Appl. Phys. 112 (5) (2012) 054512

[9] R. Tararam, E. Joanni, R. Savu, P.R. Bueno, E. Longo, J.A. Varela, Resistive-switching behavior in polycrystalline $\mathrm{CaCu}_{3} \mathrm{Ti}_{4} \mathrm{O}_{12}$ nanorods, ACS Appl. Mater. Inter. 3 (2) (2011) 500-504.

[10] M.A. Ramirez, A.Z. Simões, A.A. Felix, R. Tararam, E. Longo, J.A. Varela, Electric and dielectric behavior of $\mathrm{CaCu}_{3} \mathrm{Ti}_{4} \mathrm{O}_{12}$-based thin films obtained by soft chemical method, J. Alloy Compd. 509 (41) (2011) 9930-9933.

[11] Y.S. Shen, S.S. Ho, B.S. Chiou, Impedance spectroscopy of $\mathrm{CaCu}_{3} \mathrm{Ti}_{4} \mathrm{O}_{12}$ films showing resistive switching, J. Electrochem. Soc. 156 (6) (2009) 466-470.

[12] R. Schmidt, S. Pandey, P. Fiorenza, D.C. Sinclair, Non-stoichiometry in $\mathrm{CaCu}_{3} \mathrm{Ti}_{4} \mathrm{O}_{12}$ (CCTO) ceramic, RSC Adv. 3 (34) (2013) 14580-14589.

[13] D.F.K. Hennings, Dielectric materials for sintering in reducing atmospheres, J. Eur. Ceram. Soc. 21 (10-11) (2001) 1637-1642.

[14] L. Zhang, Z.L. Tang, Polaron relaxation and variable-range-hopping conductivity in the giant-dielectric-constant material $\mathrm{CaCu}_{3} \mathrm{Ti}_{4} \mathrm{O}_{12}$, Phys. Rev. B 70 (17) (2004) 174306, 6pp.

[15] T.B. Adams, D.C. Sinclair, A.R. West, Influence of processing conditions on the electrical properties of $\mathrm{CaCu}_{3} \mathrm{Ti}_{4} \mathrm{O}_{12}$ ceramics, J. Am. Ceram. Soc. 89 (10) (2006) 3129-3135.

[16] T.B. Adams, D.C. Sinclair, A.R. West, Decomposition reactions in $\mathrm{CaCu}_{3} \mathrm{Ti}_{4} \mathrm{O}_{12}$ ceramics, J. Am. Ceram. Soc. 89 (9) (2006) 2833-2838.

[17] J. Li, M.A. Subramanian, H.D. Rosenfeld, C.Y. Jones, B.H. Toby, A.W. Sleight, Clues to the giant dielectric constant of $\mathrm{CaCu}_{3} \mathrm{Ti}_{4} \mathrm{O}_{12}$ in the defect structure of $\mathrm{SrCu}_{3} \mathrm{Ti}_{4} \mathrm{O}_{12}$, Chem. Mater. 16 (25) (2004) 5223-5225.

[18] T.T. Fang, L.T. Mei, H.F. Ho, Effects of Cu stoichiometry on the microstructures, barrier-layer structures, electrical conduction, dielectric responses, and stability of $\mathrm{CaCu}_{3} \mathrm{Ti}_{4} \mathrm{O}_{12}$, Acta Mater. 54 (10) (2006) 2867-2875.
[19] A.A. Felix, M.O. Orlandi, J.A. Varela, Schottky-type grain boundaries in CCTO ceramics, Solid State Commun. 151 (19) (2011) 1377-1381.

[20] V.D.N. Bezzon, S.G. Antonio, C.O. Paiva-Santos, Limits of visual detection for finasteride polymorphs in prepared binary mixtures: analysis by X-ray powder diffraction, J. Pharm. Sci. 103 (11) (2014) 3567-3575.

[21] H. Rietveld, A profile refinement method for nuclear and magnetic structures, J. Appl. Crystallogr. 2 (2) (1969) 65-71.

[22] S.R. Hall, F.H. Allen, I.D. Brown, The crystallographic information file (CIF): a new standard archive file for crystallography, Acta Crystallogr. 47 (6) (1991) 655-685.

[23] International Union of Crystallography (IUCr), Crystallographic Information Framework-CIF, http://www.iucr.org/resources/cif (accessed in July 14th) (2014).

[24] R.A. Young, The Rietveld Method, Oxford University Press, Oxford, England, 1993.

[25] R.W. Cheary, A.A. Coelho, J.P. Cline, Fundamental parameters line profile fitting in laboratory diffractometers, J. Res. Natl. Inst. Stand. Technol. 109 (1) (2004) $1-25$.

[26] A.A. Coelho, Topas Academic V5, Coelho Software, Brisbane Australia, 2012.

[27] T. Yamanaka, N. Hirai, Y. Komatsu, Structure change of $\mathrm{Ca}_{1-\mathrm{x}} \mathrm{Sr}_{\mathrm{X}} \mathrm{TiO}_{3}$ perovskite with composition and pressure, Am. Mineral. 87 (8-9) (2002) 1183-1189.

[28] W.H. Baur, Atomabstaende und Bindungswinkel im Rutil, Naturwissenschaften 42 (10) (1955) 295-296.

[29] S. Asbrink, A. Waskowska, CuO: X-ray single-crystal structure determination at $196 \mathrm{~K}$ and room temperature, J. Phys. Condens. Matter 3 (42) (1991) 8173-8180.

[30] M.L. Foo, Q. Huang, J.W. Lynn, W.-L. Lee, T. Klimczuk, I.S. Hagemann, N.P. Ong, R.J. Cava, Synthesis, structure and physical properties of Ru ferrites: BaMRu$_{5} \mathrm{O}_{11}(\mathrm{M}=\mathrm{Li}$ and $\mathrm{Cu})$ and $\mathrm{BaM}_{2}{ }_{2} \mathrm{Ru}_{4} \mathrm{O}_{11}\left(\mathrm{M}^{\prime}=\mathrm{Mn}, \mathrm{Fe}\right.$ and $\left.\mathrm{Co}\right)$, J. Solid State Chem. 179 (2) (2006) 563-572.

[31] D.B. Willians, C.B. Carter, Transmission Electron Microscopy: A Textbook for Materials Science, Springer, New York U.S, 2009.

[32] K.T. Jacob, C. Shekhar, X.G. Li, G.M. Kale, Gibbs energy of formation of $\mathrm{CaCu}_{3} \mathrm{Ti}_{4} \mathrm{O}_{12}$ and phase relations in the system $\mathrm{CaO}-\mathrm{CuO} / \mathrm{Cu}_{2} \mathrm{O}-\mathrm{TiO}_{2}$, Acta Mater. 56 (17) (2008) 4798-4803.

[33] G.C. Kuczynski, N.A. Hooten, C.F. Gibson, Sintering and Related Phenomena, Gordon and Breach, New York U.S, 1967.

[34] K.M. Kim, J.H. Lee, K.M. Lee, D.Y. Kim, D.H. Hiu, S.B. Lee, Microstructural evolution and dielectric properties of $\mathrm{Cu}$-deficient and $\mathrm{Cu}$-excess $\mathrm{CaCu}_{3} \mathrm{Ti}_{4} \mathrm{O}_{12}$ ceramics, Mater. Res. Bull. 43 (2) (2008) 284-291.

[35] J.S. Reed, Principles of Ceramics Processing, Wiley, New York U.S, 1988.

[36] W.D. Kingery, H.K. Bowen, D.R. Uhlmann, Introduction to Ceramics, Wiley, New York U.S, 1976.

[37] J.L. Shi, Relations between coarsening and densification and mass transport path in solid-state sintering of ceramics: model analysis, J. Mater. Res. 14 (04) (1999) 1378-1388.

[38] P.R. Bueno, E.R. Leite, L.O.S. Bulhões, E. Longo, C.O. Paiva-Santos, Sintering and mass transport features of $(\mathrm{Sn}, \mathrm{Ti}) \mathrm{O}_{2}$ polycrystalline ceramics, J. Eur. Ceram. Soc. 23 (6) (2003) 887-896.

[39] R.M. German, Sintering Theory and Practice, Wiley, New York U.S, 1996.

[40] J.W. Cahn, The impurity-drag effect in grain boundary motion, Acta Metall. 10 (9) (1962) 789-798.

[41] L. Marchin, S. Guillemet-Fritsch, B. Durand, A.A. Levchenko, A. Navrotsky, Grain growth-controlled giant permittivity in soft chemistry $\mathrm{CaCu}_{3} \mathrm{Ti}_{4} \mathrm{O}_{12}$ ceramics, J. Am. Ceram. Soc. 91 (2) (2008) 485-489.

[42] L.C. De Jonghe, M.N. Rahaman, Sintering of ceramics, in: S. Sōmiya, F. Aldinger, N. Claussen, R.M. Spriggs, K. Uchino, K. Koumoto, M. Kaneno (Eds.), Handbook of Advanced Ceramics, Elsevier, New York, U.S, 2003.

[43] M.-J. Pan, B.A. Bender, A bimodal grain size model for predicting the dielectric constant of calcium copper titanate ceramics, J. Am. Ceram. Soc. 88 (9) (2005) $2611-2614$

[44] T.T. Fang, H.K. Shiau, Mechanism for developing the boundary barrier layers of $\mathrm{CaCu}_{3} \mathrm{Ti}_{4} \mathrm{O}_{12}$, J. Am. Ceram. Soc. 87 (11) (2004) 2072-2079.

[45] S.G. Kim, Y.B. Park, Grain boundary segregation, solute drag and abnormal grain growth, Acta Mater. 56 (15) (2008) 3739-3753.

[46] E.J. Payton, G. Wang, M.J. Mills, Y. Wang, Effect of initial grain size on grain coarsening in the presence of an unstable population of pinning particles, Acta Mater. 61 (4) (2013) 1316-1326.

[47] P.R. Rios, Abnormal growth in the presence of coarsening particles, Acta Metall. 40 (4) (1992) 649-651.

[48] K.M. Kim, S.J. Kim, J.H. Lee, D.Y. Kim, Microstructural evolution and dielectric properties of $\mathrm{SiO}_{2}$-doped $\mathrm{CaCu}_{3} \mathrm{Ti}_{4} \mathrm{O}_{12}$ ceramics, J. Eur. Ceram. Soc. 27 (13-15) (2007) 3991-3995. 